\title{
Doctors call for divestment from fossil fuels
}

$\mathrm{F}$ or a third year in a row, a group of eco-conscious physicians will campaign at the Canadian Medical Association (CMA) General Council Aug. 23-26 for physician associations to divest from fossil fuels and reinvest in renewable energy.

The international divest-invest movement, which has been gaining momentum since it began in 2012, is making inroads into the medical community. In 2014, the British Medical Association committed to divesting from fossil fuels and The Royal Australasian College of Physicians followed suit in June.

The CMA has over \$29 million in investments with $6 \%$ (\$1.77 million) in the energy sector. More than 43000 physicians invest with CMA's subsidiary, MD Financial Management, including Dr. Courtney Howard, an emergency doctor in Yellowknife. She is spearheading the move for divestment alongside the Canadian Association of Physicians for the Environment (CAPE), which has over 6000 members. Right now, physicians can choose socially responsible investing through third-party funds, but for Howard and others that doesn't go far enough.

"We're looking to ask the CMA to divest its reserves from fossil fuels and to invest in renewable energy as a bit of an informational sign post for Canadians that Canadian physicians do view climate change as a human health issue and prioritize climate action."

Last year, Howard and her husband, a pediatrician, decided to divest. "Basically, we paid an outside consultant to help us create a balanced portfolio with reduced carbon risk and investments in renewable energy and then used MD Financial's web portal to buy the financial products."

Howard will make a case for divestment when she attends CMA's General Council in Halifax as a delegate for the Northwest Territories Medical Association. "Most Canadians don't connect climate change to human health. Given

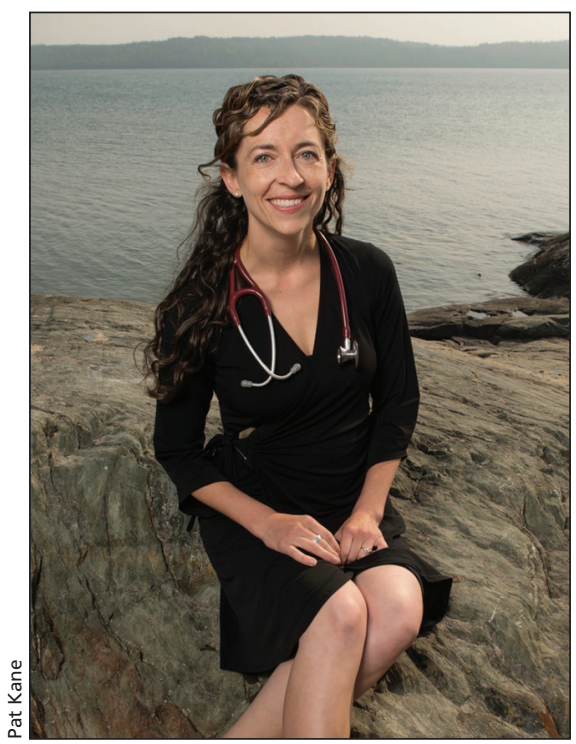

Courtney Howard, a physician in Yellowknife, is helping to lead the movement to divest from fossil fuels.

all of the information that has been in medical journals about it that's a real failure of communication on the part of our profession."

She will call for the CMA, as well as The College of Family Physicians of Canada (CFPC) and the Royal College of Physicians and Surgeons of Canada to divest from fossil fuels. The CMA declined to comment until after general council; the other two associations said they won't comment until they hear more requests from members.

In the summer of 2014, Howard said she witnessed the effect climate change when Yellowknife was cloaked in heavy smoke from area wildfires and she noted more patients wheezing in her emergency department. She intends to research the health effects of wildfires.

The increasing instances of wildfires in North America can be linked to climate change, says Dr. Trevor Hancock, cofounder of CAPE, the Canadian affiliate of the International Society of Doctors for the Environment. "We have an ethical duty not to create conditions or support the creation of conditions that will harm our patients."
Recently, climate change has been framed as a public health issue. This year, the 2015 Lancet Commission on Health and Climate Change published studies linking climate change and public health; the World Health Assembly approved the first international resolution aimed at combatting air pollution; and, on Aug. 3, the White House unveiled its Clean Power Plan to dramatically cut emissions from US power plants.

In December, world leaders will meet at the United Nations Climate Change Conference in Paris in an effort to achieve a legally binding and universal agreement. According to scientists keeping the world temperature from rising more than two degrees means that more than two-thirds of fossil fuel reserves have to stay in the ground. In light of this, divestment, according to Howard and Hancock, is a financially prudent choice.

Not all of the external investment managers hired by MD Financial Management necessarily share that view, says the Executive Vice President of Member Solutions Mike Gassewitz, but $\mathrm{MD}$ is hearing enough anecdotes to warrant some changes.

"As we listen more we gain an understanding of where folks are coming from. I think when the initial topic comes up it's very much in the context of reducing carbon emissions and doing what many physicians feel is right for the environment and people's health."

Over the next few months, MD Financial Management will conduct research, including online focus groups, to consider providing the option to clients of whether they want to eliminate or reduce carbon from their portfolio. Regardless of whether Howard is able to persuade her fellow Canadian physicians to divest or not, Gassewitz says, "we feel there is enough of a demand out there to at least pull something together."Shannon Lough, CMAJ

CMAJ 2015. DOI:10.1503/cmaj.109-5131 